\title{
Psychometric properties of the scale for non-adherence to antiretroviral medication (NAME) among HIV-infected patients
}

\author{
Zahra Hosseini ${ }^{1}$, Hassan Eftkhar ${ }^{2}$, Teamur Aghamolaei ${ }^{* *}$, Abbas Ebadi ${ }^{3}$, Saharnaz Nedjat ${ }^{4}$, Ladan Abbasian ${ }^{5}$ and \\ Mina Hashemiparast ${ }^{6}$
}

\begin{abstract}
Background: Adherence to HIV medication is necessary for long-term HIV disease management. The objective of this study was to develop and examine the psychometric properties of a scale for measuring the barriers of antiretroviral medication adherence among Iranian Patients.

Method: This was a sequential, exploratory mixed methods investigation composed of two phases. In the qualitative phase, item pool generation and questionnaire designing was carried out through in-depth individual interviews and group discussions; in the quantitative phase, psychometric properties of the questionnaire were assessed. In both phases, the participants were people who were living with HIV/AIDS and were taking antiretroviral medications.

Results: In the first phase, an item pool containing 181 statements related to barriers of adherence to antiretroviral medication was generated. In the second phase, item reduction was applied, and a questionnaire containing 30 items was developed. The psychometric properties of the questionnaire were assessed, which indicated good validity and reliability of the instrument. In exploratory factor analysis, the items were loaded on six factors that altogether explain for 61.98 of the variance. The Cronbach's alpha and the intra class correlation coefficient of the questionnaire was 0.91 and 0.80 , respectively.

Conclusion: This study provided a reliable and valid instrument to identify the barriers of adherence to antiretroviral medication in patients with HIV/AIDS. Identify these barriers and design of interventions to eliminate or reduce of barriers can be an effective means of enhancing adherence to antiretroviral medication among these patients.
\end{abstract}

Keywords: Barriers of adherence, Antiretroviral medication, HIV, AIDS, Adherence questionnaire

\section{Background}

Considering the main routes of transmission of human immunodeficiency virus (HIV), are sexual contact and drug injecting, HIV/AIDS can be classified as a behavioral disease as it relates to the most personal aspects of life. Hence, it is obvious that silence and secrecy are major characteristics of this disease and seeking medical care is avoided. Due to the nature of disease, including the long incubation period (during which there are no signs of the disease), results in delays in the diagnosis of HIV/AIDS and initiation of preventive measures. During this period,

\footnotetext{
* Correspondence: teaghamolaei@gmail.com

${ }^{1}$ Social Determinants in Health Promotion Research Center, Hormozgan Health Institute, Hormozgan University of Medical Sciences, Bandar Abbas, Iran Full list of author information is available at the end of the article
}

patients may unwittingly spread the virus to others [1]. The most common and known antiretroviral medication regimen is highly active antiretroviral therapy (HAART), that considerably limits the spread of the virus in the body [2]. The objective of antiretroviral therapy is preventing disease progression, enhancing the quality of life, and prolonging life. The key to successfully meeting these objectives is the desire and willingness of people with HIV to adhere to the antiretroviral regimen. Adherence to therapy means the correct use of each of the antiretroviral medication doses, at the proper time and exactly as it is prescribed [3, 4]. Based on recent reports, approximately $60 \%$ of Iranian patients with HIV/AIDS who are adhere to therapy with antiretroviral medications [5]. Adherence to antiretroviral medications among people living with HIV/ 
AIDS is affected by many different factors. In most studies, the level of adherence to antiretroviral medications is measured [6-8]. Some studies have dealt with effective factors on adherence to HIV medication $[8,9]$. There are different questionnaires for the adherence to therapy such as the Morisky questionnaire and self-reported questionnaire assessing adherence to antiretroviral medication and patient medication adherence questionnaire (PMAQ) [10-12]. Also the adherence to medication questionnaire, validated by Ira Wilson's, is useful for early identification of people who do not adhere to medication [13]. In Iran, Access to information of AIDS patients is restrict because of the social stigma and the need to keep it a secret. Besides, Patients are reluctant to participate in the study because of fear of disease disclosure. so,few studies have been done in Iran on the treatment of patients with HIV/ AIDS. In and does not exist a indigenous tool adapted to Iranian culture for check the barriers of adherence to antiretroviral medication. Thus, the main objective of this study was to develop an instrument for measuring the barriers of adherence to antiretroviral medication.

\section{Method}

The sequential, exploratory mixed methods study was conducted in two phases: first, a qualitative study was carried out for item pool generation and designing the instrument; and second, a quantitative approach was used to evaluate the questionnaire.

First phase: item pool generation and instrument design Information from in-depth individual interviews and group discussions were used for item pool generation and designing the instrument.

\section{Participants}

The participants had serologic evidence of HIV/AIDS and were being treated with antiretroviral medications. The entrance criteria of the study included having a first-hand experience regarding the study objective (People with HIV/AIDS who are treated with antiretroviral medication and who experience regular or irregular use of these medication and they can give us complete information), being able to speak Persian, and having enough time for interviews or group discussions. Participants were people who were referring to the AIDS center of Imam Khomeini Hospital affiliated to Tehran University of Medical Sciences for taking the antiretroviral medication. Sampling was through a purposeful method with maximum variation so that participants had different experiences regarding HIV/AIDS. The participants represented different age ranges, education levels, occupations, and included both male and female patients. Patients were selected irrespective of whether they had been hospitalized, experienced drug abuse, or demonstrated a good antiretroviral medication adherence.

We used in-depth semi structured interviews with open-ended answers and group discussions for data collection. Usually, the interviews started with the following two questions: (1) How is your life going on with this virus (HIV)? and (2) What therapeutic measures have you taken until now? The subsequent questions were based on the patients' answers. During the interview we asked the participants for their experiences of illness and therapeutic measures and the factors affecting their adherence to antiretroviral medication. we also used some questions to deepen the interview, such as: what do you mean? Explain more? I understand this from your conversation is it right? After 32 interviews and two group discussions, data saturation was reached. It is noteworthy that we also interviewed two nurses working in infectious ward and one infectious disease specialist.

\section{Data analysis}

Conventional content analysis was applied. The analysis of the data obtained from each interview was carried out before the next interview and it was carried out based on the semantic load of what the participants uttered. Finally, the semantic units were extracted, and each of them became an item of the questionnaire. For example, one of the patients said: "There were many factors that caused me not to take my medications. I was a child, and the school did not register me saying that if I contacted other children they would be infected as well, and this left me with a very bad feeling," This semantic unit became an item in the questionnaire, which stated: "bad feeling caused by discrimination in comparison with healthy people in the society." Another patient said: "It was very difficult for me to know I should take medication all during my life." This statement became an item in the questionnaire, which stated "lifetime medication use." Finally, a total of 181 items were extracted. After the research team had investigated the items during several sessions, similar items were merged or eliminated, and the semantic and literature structure of the items were modified. Finally, 61 items constituted the basic version of the questionnaire, and the instrument entered the psychometric evaluation phase.

\section{Second phase: psychometric evaluation of the barriers of antiretroviral medications adherence scale in HIV/AIDS patients}

The basic draft of the questionnaire was designed based on the data gathered through individual interviews,group discussions and themes extracted from related studies, which included 61 items with a five-point Likert scale (ranging from very much with a score of 5 to never with a score of 1$)$. 


\section{Face validity}

We applied both qualitative and quantitative methods for identifying the face validity. Ten people who were being treated with HAART assessed each item regarding the difficulty level, appropriateness, possible ambiguity, and complexity. For quantitative face validity and impact score (frequency * importance), the same patients were asked to evaluate the instrument and score the importance of each item based on the five-point Likert scale [14].

\section{Content validity}

Qualitative and quantitative content validity was conducted by ten experts (professors in health education and promotion, infection specialists, and professors of nursing in the field of toolmaking), who evaluated the content coverage, compliance with grammar, use of appropriate phrases, and proper placement of items for each aspect. In the quantitative phase, CVI (Content Validity Index) and CVR (Content Validity Ratio) were calculated. For CVR, Lawshe's method was applied to check how essential an item is for the questionnaire; the experts investigated each item based on a three-part spectrum as follows: is essential, is helpful but not essential, and not necessary. Based on Lawshe's table, the items with CVR value of 0.62 or above were accepted [15]. For CVI, the same experts checked the items for relevancy, according to Waltz \& Bausell's recommendation and based on a four-point Likert scale scored the items [16].

\section{Statistical analysis and sampling (construct validity)}

Exploratory factor analysis was applied to determine the underlying constructs of the questionnaire. The sample size was calculated based on the number of items (31 items) in the questionnaire. A total of 264 patients with HIV/AIDS treated with HAART for 6 months were selected. After performing the Kaiser-Mayer-Olkin (KMO) index and Bartlett's test, a principle component analysis with equimax rotation was applied, and the factor loading equal to or greater than 0.3 was considered acceptable.

\section{Reliability of the instrument}

To check the internal consistency of the questionnaire, the Cronbach's alpha was calculated [17]. Test - Re-test with using intra class correlation coefficient (ICC) was calculated to assess the external consistency of the questionnaire [18]. All statistical analyses were carried out using SPSS software, version 18.

\section{Results}

All 264 study participants completed the questionnaire. The average age of the participants was 39 years (standard deviation $[\mathrm{SD}]=9.3$ years). The average period of disease diagnosis was 96.81 months. The minimum diagnosis time was 6 months, and the maximum was 384 months or 32 years ( $\mathrm{SD}=79.03$ months). The average time of starting HAART was 61.96 months, and the minimum of having started antiretroviral therapy was 6 months and the maximum was 336 months or 28 years (Table 1).

\section{Face validity}

In qualitative face validity, six items that were reported to be difficult to understand were modified. In quantitative face validity, 11 items that had gained scores below 1.5 were eliminated, and finally, 51 items were preserved for the next steps.

\section{Content validity}

To test the qualitative content validity the wordings of some items were modified according to the experts' opinions. In the quantitative phase, based on Lawshe's table, 19 items having scores of less than 0.62 were eliminated and the rest of the items saved. In the evaluation of CVI, based on the Waltz \& Bausell's index, all 31 items gained a score of higher than 0.79 . Hence, the questionnaire entered the construct validity phase with 31 items.

\section{Construct validity}

Kaiser-Mayer-Olkin (KMO) index and Bartlett's test of sphericity indicated that the data was appropriate for the factor analysis KMO index $=0.878, \mathrm{X}^{2}=4440.737, P=$ 0.000). Based on the results of the analysis, six factors were extracted. As explained in Table 2, each of the six factors had an eigenvalue $>1$, and six factors jointly accounted for $61.98 \%$ of the variance observed.

Table 1 Demographic characteristics of the study sample

\begin{tabular}{lll}
\hline & Number & Percentage \\
\hline Sex & 121 & 45.8 \\
Female & 143 & 54.2 \\
Male & & \\
Marital status & 51 & 19.3 \\
Single & 105 & 39.8 \\
Married & 46 & 17.4 \\
Spouse died & 62 & 23.5 \\
Divorced & & \\
Educational level & 11 & 4.2 \\
Illiterate & 119 & 45.1 \\
Not having high school diploma & 97 & 36.7 \\
High school diploma & 20 & 7.6 \\
Associate degree & 12 & 4.5 \\
Bachelor (B.A., B.S.) & 5 & 1.9 \\
Master degree (M.A., M.S.) & & \\
Drug abuse experience & 103 & 39 \\
Yes & 161 & 61 \\
No & & \\
\hline
\end{tabular}


Table 2 Eigenvalue and variance's total percentage identified by six extracted factors

\begin{tabular}{|c|c|c|c|c|c|c|c|c|c|}
\hline \multirow[t]{2}{*}{ Factor } & \multicolumn{3}{|c|}{ Eigenvalue } & \multicolumn{3}{|c|}{ Collection of extracted factor loads } & \multicolumn{3}{|c|}{ Collection of rotated factor loads } \\
\hline & Total & $\begin{array}{l}\text { Variance } \\
\text { percentage }\end{array}$ & $\begin{array}{l}\text { Cumulative } \\
\text { percentage }\end{array}$ & Total & $\begin{array}{l}\text { Variance } \\
\text { percentage }\end{array}$ & $\begin{array}{l}\text { Cumulative } \\
\text { percentage }\end{array}$ & Total & $\begin{array}{l}\text { Variance } \\
\text { percentage }\end{array}$ & $\begin{array}{l}\text { Cumulative } \\
\text { percentage }\end{array}$ \\
\hline Personal barriers & 9.8 & 32.66 & 32.66 & 9.80 & 32.66 & 32.66 & 4.06 & 13.53 & 13.53 \\
\hline Medical challenges & 2.37 & 7.91 & 40.58 & 2.37 & 7.91 & 40.58 & 3.64 & 12.14 & 25.67 \\
\hline Quality of services & 1.87 & 6.25 & 46.83 & 1.87 & 6.25 & 46.83 & 2.90 & 9.60 & 35.34 \\
\hline Financial problems & 1.97 & 5.90 & 52.81 & 1.79 & 5.98 & 52.81 & 2.83 & 9.46 & 44.80 \\
\hline Perceived support & 1.48 & 4.95 & 57.77 & 1.48 & 4.95 & 57.77 & 2.64 & 8.80 & 53.61 \\
\hline Disclosure of the disease & 1.26 & 4.21 & 61.98 & 1.26 & 4.21 & 61.98 & 2.51 & 8.37 & 61.98 \\
\hline
\end{tabular}

Among the 31 items, one item was eliminated because of not being congruent with the rest of items and showing low correlation with the rest of the items. Finally, 30 items of the questionnaire were loaded on the six factors (Table 3).

\section{Internal and external reliability}

The Cronbach's alpha for the entire questionnaire was 0.91 and for the subscales ranged from 0.7 to 0.88 . The test - Re-test for the entire questionnaire was 0.80 and for the subscales ranged from 0.57 to 0.75 , that providing support to the stability of the questionnaire.

\section{Discussion}

The purpose of this study was to develop and evaluate an instrument for assessing barriers of adherence to antiretroviral medication in HIV/AIDS people. The final questionnaire was checked for validity and reliability with 30 items in 6 subscales (personal barriers, medical challenges, financial problems, perceived support, quality of services, and disclosure of the disease). The CVI and CVR indicated an acceptable validity, and the Cronbach's alpha and ICC also showed acceptable values, indicating a desirable reliability of the questionnaire. This questionnaire assesses the barriers of adherence to antiretroviral medication among people living with HIV/AIDS.

The subscale of personal barriers indicates the issues that each person experiences independent of others and with minimum effect on the environment. Barriers classified in this category include a lack of awareness and knowledge regarding the disease, therapy and the importance of the regular use of the medications, and depression. Peoples infected with HIV who are aware that not taking their medications or irregularly taking it, will result in the progression to AIDS, will show higher adherence to antiretroviral medications. In addition, depression and hopelessness are quite common among people living with HIV/AIDS, with nearly all participants reporting that they have experienced depression during their disease course, noting that depression decreased their motive for life and hope for the future. The subscale of services quality indicated the existence of some unprofessional behavior from the medical staff, including bad behavior (Rude behavior with insults and disregard to patients) and insufficient consultation, which created challenging circumstances for the patients regarding the start, continuance, and follow-up of their therapy.

The subscale of medical challenges explains the nature of therapy and its influence on the regular use of medications. The obligation of long-term, lifetime use of the medications causes fatigue and forgetfulness of medications doses. Moreover, the medications have some side effects, and it is difficult for the patients to cope with them. All these problems reduce adherence to antiretroviral medications among people living with HIV/AIDS. The subscale of perceived support deals with the fact that these people are rejected and neglected by both their family and the society and are treated unkindly; hence, they lose their motivation for therapy. The subscale of financial problems reveals such problems as reduction of incomes and poverty among these patients that further complicates the process of continuous therapy. Most of the patients dealing with this disease belong to the low socio-economic class and are drug abusers; hence, therapy is not a priority for them and they cannot afford the therapy costs. The subscale of the disclosure of the disease explains the patients' worries regarding the disclosure of data about their HIV/AIDS status for their family, medical team, and other members of the society, due to the fear of stigma and discrimination.

As per our knowledge, there is no questionnaire that assesses the barriers of adherence to antiretroviral medications hence, we were unable to establish a comparison with the questionnaire designed for this study. However, some questionnaires assess adherence to the therapy; for example, Morisky's medication adherence scale. This questionnaire is mainly used for chronic diseases and includes four questions: (1) Do you ever forget to take your medicine? (2) Are you careless at times about taking your medicine? (3) Sometimes if you feel worse when you take the medicine, do you stop taking it? and (4) When you feel better, do you sometimes stop taking your medicine? This questionnaire is designed with two option answers (positive or negative), which evaluates the patients' adherence to therapy, and the number of questions is limited [10]. 
Table 3 Factors, items, and extracted factor loads of the factor analysis with equimax rotation

\begin{tabular}{|c|c|c|}
\hline Factor & Items & Factor load \\
\hline \multirow[t]{8}{*}{ Personal barriers } & 1. Not admitting the disease and not being able to cope with it & 0.751 \\
\hline & 2. Lack of mental preparation for taking medicines & 0.693 \\
\hline & $\begin{array}{l}\text { 3. Not being informed of the fact that through using medicines you } \\
\text { will experience a normal lifetime }\end{array}$ & 0.683 \\
\hline & 4. Lack of awareness of the proper use of the medicines & 0.649 \\
\hline & 5. Uncertainty about the effectiveness of the medicines & 0.630 \\
\hline & 6. Considering life and health as unimportant & 0.600 \\
\hline & 7. Feeling of hopelessness and depression & 0.490 \\
\hline & 8. Lack of awareness of the risk of developing medicine resistance & 0.389 \\
\hline \multirow[t]{6}{*}{ Medical challenges } & 9. Getting tired of constantly taking medicines & 0.477 \\
\hline & 10. Large amount of pills to be taken daily & 0.732 \\
\hline & 11. Being lazy in taking medicines & 0.687 \\
\hline & 12. Forgetting to take medication & 0.645 \\
\hline & 13. Medicine's side effects & 0.430 \\
\hline & $\begin{array}{l}\text { 14. Interference of the medications with the joy received by abusing } \\
\text { alcohol and drugs }\end{array}$ & 0.363 \\
\hline \multirow[t]{6}{*}{ services quality } & 15. Not having enough and proper access to consultation services & 0.730 \\
\hline & 16. Not receiving empathy from your physician & 0.658 \\
\hline & 17. Waiting for a long time to receive medicine and visit a doctor & 0.516 \\
\hline & 18. Lack of needed medicines in therapeutic centers & 0.597 \\
\hline & 19. Insufficient guidance of medical staff & 0.454 \\
\hline & 20. Bad behavior of medical staff & 0.365 \\
\hline \multirow[t]{2}{*}{ Financial problems } & 21. The cost of traveling to therapy centers for medicines & 0.837 \\
\hline & 22. The cost of medical tests & 0.779 \\
\hline \multirow[t]{4}{*}{ Perceived support } & $\begin{array}{l}\text { 23. Not having someone to remind you when you should take the } \\
\text { medicines }\end{array}$ & 0.845 \\
\hline & 24. Not having family care or supervision in taking medicines & 0.835 \\
\hline & 25. Lack of family emotional support & 0.531 \\
\hline & 26. Not having Emotional connection with other patients living with HIV & 0.406 \\
\hline \multirow[t]{4}{*}{ Disclosure of the disease } & 27. Fear of the disclosure of the disease while taking medicines & 0.757 \\
\hline & $\begin{array}{l}\text { 28. Bad feeling caused by discrimination in comparison with healthy } \\
\text { people in the society }\end{array}$ & 0.707 \\
\hline & 29. Fear of others seeing the medicines & 0.647 \\
\hline & 30. Not going to take the medicines because your privacy is not preserved & 0.606 \\
\hline
\end{tabular}

Our questionnaire investigates different areas with multiple items and solely concentrates on the adherence of people living with HIV/AIDS to antiretroviral medications. The questions presented in the Morisky questionnaire are compatible with some of the items of our questionnaire that are classified under the subscale of medical challenges, including a modified version of the Morisky questionnaire with eight questions [10]. The Morisky questionnaire has been applied in different studies for evaluating the level of adherence to therapy [19-22]. Self-efficacy questionnaire on the use of antiretroviral medication that valided by Joudith. Self efficacy is an important factor in medication use [23]. Our questionnaire does not have a self efficacy sub- scale but some items in sub-scale of Medical challenges, indicates a lack of self efficacy in the patients who that taking antiretroviral medications.

MARS is another questionnaire used for evaluating the level of adherence to therapy among those suffering from psychotic disorders. This questionnaire is designed and psychometrically evaluated by Thompson and includes ten items. In this questionnaire, the patients are required to answer items regarding their attitude and performance of the way they used their medication within the past week. The items of this questionnaire are similar to some of the items of our questionnaire classified under the subscales of personal barriers and medical 
challenges [24]. Morisky and Thompson questionnaires are not suitable for investigating adherence to antiretroviral medications among people living with HIV/AIDS because AIDS is not similar to other chronic diseases. In Iran AIDS is not only a health problem but also a social dilemma and the society consider the HIV/AIDS patients as sinners, Which causes social deprivation of patients. That's why patients try to hide their illness.

Each society is based on certain traditional and cultural beliefs. The role and effect of these factors are different in different societies. In Iran, traditional and socio-cultural factors have been integrated and AIDS and its therapy are strongly influenced by mentioned factors. The strength of this study is that the questionnaire is designed based on these factors.

\section{Limitations}

The researchers of this study did their best to design a questionnaire that covers all noted aspects; however, this study also faced some limitations: Talking about AIDS is constrained by some ethical and conventional considerations in the context of Iran. The fact that someone is infected with this virus causes moral stigma in the society, and therefore, it is likely that participants do not express the whole reality about themselves, their disease, and their therapy process. These issues can negatively affect the comprehensiveness of the questionnaire. Moreover, performing additional tests such as confirmatory factor analysis is recommended.

\section{Conclusion}

We believe that this questionnaire provides useful information for the health education and promotion specialists and infectious disease specialists so that they can obtain a deeper and more accurate understanding of the barriers of the adherence to antiretroviral medication among patients with HIV/AIDS and take effective steps for promoting the behavior of adherence to antiretroviral medication.

\section{Abbreviations \\ AIDS: Aquired Immune Deficiency Syndrom; CVI: Content Validity Index; CVR: Content Validity Ratio; HAART: Highly Active Antiretroviral Therapy; HIV: Human Immune Deficiency Virus; KMO: Kaiser-Meyer-Olkin; MARS: Medication Adherence Rating Scale; SD: Standard Deviation}

\section{Acknowledgements}

The authors would like to thank Tehran University of Medical Science for the financial support. And also likes to acknowledge all who participated in or collaborated with the current study.

\section{Authors' contributions}

Conceptualization: ZH,HE,TA. Methodology: ZH, SN, HE. Data analysis: $\mathrm{ZH}, \mathrm{HE}, \mathrm{LA}$,TA. Original draft preparation: $\mathrm{ZH}$ and TA. Review and edits: $\mathrm{ZH}, \mathrm{MH}$. All authors read and approved the final version of the manuscript.

\section{Funding}

This project was funded by Tehran University of Medical Sciences.

\section{Availability of data and materials}

The datasets used and analysed during the current study are available from the corresponding author on reasonable request.

\section{Ethics approval and consent to participate}

The participation in the study was voluntary, and the participants were free to withdraw from the study at any time. Participants received an adequate and understandable explanation about the intent and possible outcomes of the study, the participants signed an informed consent form. The study was approved by Ethical Committee for Tehran University of Medical Sciences.

\section{Consent for publication}

Not applicable.

\section{Competing interests}

The authors declare that they have no competing interests.

\section{Author details}

${ }^{1}$ Social Determinants in Health Promotion Research Center, Hormozgan Health Institute, Hormozgan University of Medical Sciences, Bandar Abbas, Iran. 2Department of Health Education and Promotion, School of Health, Tehran University of Medical Sciences, Tehran, Iran. ${ }^{3}$ Behavioral Sciences Research Center (BSRC), Life Style Institute, Faculty of Nursing, Baqiyatallah University of Medical Sciences, Tehran, Iran. ${ }^{4}$ Department of Epidemiology and Biostatistics, School of Health, Tehran University of Medical Sciences, Tehran, Iran. ${ }^{5}$ Iranian Research Center of HIV/AIDS, Iranian Institute for Reduction of High-Risk Behaviors, Tehran University of Medical Sciences, Tehran, Iran. 'Department of Public Health, Maragheh University of Medical Sciences, Maragheh, Iran.

Received: 4 August 2019 Accepted: 22 November 2019

Published online: 06 December 2019

\section{References}

1. Chapman Lambert C, Westfall A, Modi R, Amico RK, Golin C, Keruly J, Quinlivan EB, Crane HM, Zinski A, Turan B, Turan JM, Mugavero MJ. HIVrelated stigma, depression, and social support are associated with healthrelated quality of life among patients newly entering HIV care. AIDS Care. 2019 Jun;5:1-8. https://doi.org/10.1080/09540121.2019.1622635.

2. Abdulrahman SA, Ganasegeran K, Rampal L, Martins OF. HIV Treatment Adherence - A Shared Burden for Patients, Health-Care Providers, and Other Stakeholders. AIDS Rev. 2019;21(1):28-39. https://doi.org/10.24875/AIDSRev. 19000037

3. Althoff KN, Smit M, Reiss $P$, Justice AC. HIV and ageing: improving quantity and quality of life. Curr Opin HIV AIDS. 2016 Sep;11(5):527.

4. Holstad MM, Dilorio C, Kelley ME, Resnicow K, Sharma S. Group motivational interviewing to promote adherence to antiretroviral medications and risk reduction behaviors in HIV infected women. AIDS Behav. 2011;15:885-96. 21165692.

5. Khalili H, Rohani R, Seyedalinaghi S, Hajiabdolbaghi M, Dashti-Khavidaki S, Talasaz AH. Adherence to Antiretroviral Therapy Among Iranian HIV/AIDS Patients. Curr Clin Pharmacol. 2012;7(2). 22432842.

6. Peltzer K, Pengpid S. Socioeconomic factors in adherence to HIV therapy in low- and middle-income countries. J Health Popul Nutr. 2013;31(2):150-70. 23930333.

7. Vreeman RC, Scanlon ML, Tu W, Slaven JE, McAteer Cl, Kerr SJ, Bunupuradah T, Chanthaburanum S, Technau KG, Nyandiko WM. Validation of a self-report adherence measurement tool among a multinational cohort of children living with HIV in Kenya, South Africa and Thailand. J Int AIDS Soc. 2019 May;22(5):e25304.

8. Lyimo RA, de Bruin $\mathrm{M}$, van den Boogaard J, Hospers $\mathrm{HJ}$, van der Ven A, Mushi D. Determinants of antiretroviral therapy adherence in northern Tanzania: a comprehensive picture from the patient perspective. BMC Public Health. 2012;12:716. 9.1186/1471-2458-12-716.

9. Adeniyi OV, Ajayi Al, Ter Goon D, Owolabi EO, Eboh A, Lambert J. Factors affecting adherence to antiretroviral therapy among pregnant women in the Eastern Cape, South Africa. BMC Infect Dis. 2018;18:175.

10. Morisky DE, Green LW, Levine DM. Concurrent and predictive validity of a selfreported measure of medication adherence. Med Care. 1986;24:67-74. 3945130

11. Duong M, Piroth L, Grappin M, Forte F, Peytavin G, Buisson M, Chavanet P, Portier $\mathrm{H}$. Evaluation of the patient medication adherence questionnaire as a tool for self-reported adherence assessment in HIV-infected patients on antiretroviral regimens. HIV Clin Trials. 2001;2(2):128-35. 
12. Godin G, Gagné C, Naccache H. Validation of a self-reported questionnaire assessing adherence to antiretroviral medication. AIDS Patient Care STDs. 2003;17(7):325-32.

13. Wilson IB, Lee Y, Michaud J, Fowler FJ Jr, Rogers WH. Validation of a new three-item self-report measure for medication adherence. AIDS Behav. 2016; 20(11):2700-8.

14. Bolarinwa OA. Principles and methods of validity and reliability testing of questionnaires used in social and health science researches. Nig Postgrad Med J. 2015 Oct 1;22(4):195.

15. Lawshe $\mathrm{CH}$. A quantitative approach to content validity 1. Pers Psychol. 1975 Dec;28(4):563-75.

16. Waltz CF, Strickland OL, Lenz E. Measurement in nursing and health research, Springer publishing company, Fifth Edition, chapter 2. 2017;183-210.

17. Polit $\mathrm{D}$, Beck $\mathrm{CH}$. Essentials of Nursing Research: appraising evidence for nursing practice: 370-375. 7th edition. Philadelphia: LWW. 2008.

18. Plichta SB, Kelvin EA. Munro's statistical methods for health care research. 2013. Wolters Kluwer Health/Lippincott Williams \& Wilkins.(ETS) exposure in pediatric cancer patients. Pediatric blood \& cancer. 2009;52(5):644-9.

19. Tordoff JM, Bagge ML, Gray AR, Campbell AJ, Norris PT. Medicine-taking practices in community-dwelling people aged $\geq 75$ years in New Zealand. Age Ageing. 2010 Jun 17;39(5):574-80.

20. Berni A, Ciani E, Cecioni I, Poggesi L, Abbate R, Boddi M. Adherence to antihypertensive therapy affects ambulatory arterial stiffness index. Eur J Intern Med. 2011;22(1):93-8. 21238902.

21. Krousel-Wood M, Islam T, Webber LS, Re R, Morisky DE, Muntner P. New medication adherence scale versus pharmacy fill rates in hypertensive seniors. Am J Manag Care. 2009 Jan;15(1):59.

22. Babamoto KS, Sey KA, Camilleri AJ, Karlan VJ, Catalasan J, Morisky DE. Improving diabetes care and health measures among hispanics using community health workers: results from a randomized controlled trial. Health Educ Behav. 2009 Feb;36(1):113-26.

23. Erlen JA, Cha ES, Kim KH, Caruthers D, Sereika SM. The HIV medication taking self-efficacy scale: psychometric evaluation. J Adv Nurs. 2010 Nov 66(11):2560-72.

24. Thompson K, Kulkarni J, Sergejew AA. Reliability and validity of a new medication adherence rating scale (MARS) for the psychoses. Schizophr Res. 2000 May 5:42(3):241-7.

\section{Publisher's Note}

Springer Nature remains neutral with regard to jurisdictional claims in published maps and institutional affiliations.

Ready to submit your research? Choose BMC and benefit from:

- fast, convenient online submission

- thorough peer review by experienced researchers in your field

- rapid publication on acceptance

- support for research data, including large and complex data types

- gold Open Access which fosters wider collaboration and increased citations

- maximum visibility for your research: over $100 \mathrm{M}$ website views per year

At $\mathrm{BMC}$, research is always in progress.

Learn more biomedcentral.com/submissions 